\title{
Comparative Study of Diagrid, Simple Frame and Shear Wall System
}

\author{
Viraj Baile*, Dr. A.A. Bage** \\ *(M. Tech Student, Structural Engineering, Sardar Patel College of Engineering, Andheri, Maharashtra, India \\ Email:virajbaile@gmail.com) \\ ** (Associate Professor, Structural Engineering, Sardar Patel College of Engineering, Andheri, Maharashtra, \\ India Email: a_bage@spce.ac.in)
}

\begin{abstract}
Diagrid Structure is one of the most unique structural systems that has been developed in recent years. For designing tall buildings there are various structural systems such as moment resisting frame, shear wall system, bracing system, space trusses, tubular structures etc. Diagrid is one of the new structural systems which is adept for designing tall buildings. In this paper, a comparative study between diagrid system, simple frame system and bracing system has been put forth. A 36-storeyed diagrid building, simple frame building and a building with Shear wall systems have been modelled and analyzed. The shear wall systems are provided as L-shaped at corners, provided at middle and provided at the core. The positions of the bracings have also been varied. A total of 12 buildings have been modelled and analyzed to compare which system performs better a lateral load resisting system. The modelling and analysis has been performed on ETABS. The dynamic analysis is performed by using Response Spectrum Method. All the loadings and the checks are provided as per Indian Standards.
\end{abstract}

Keywords: Comparative Study, Diagrid Structure, Dynamic Analysis, Lateral Load Resisting Systems, Shear Wall System.

\section{INTRODUCTION}

Designing tall buildings has become a necessity due to increase in population, scarcity of land and environmental issues. The desire for aesthetics in urban settings and human aspiration to build higher also contribute for the same. Thus, this has led to development and evolution of many structural systems. Some of the structural systems used for designing of tall buildings are shear wall system, rigid frame, moment frame system, braced frame system, outrigger system, core structure system, tubular structures, bundled tube, frame tube system, diagrid system etc. The main reason for developing these systems is to effectively increase the lateral load resisting capacity of the structure while maintaining the economy because for tall structures the governing factor is lateral loads contributed by wind (earthquake load is also factored in but for tall structures wind plays the dominant role). In this paper following lateral load resisting systems have been analysed and compared: 1) Simple Frame Structure (Moment Resisting Frame): In this system, the lateral forces generated and primarily resisted by rigid frame action i.e. by development of shear force and bending moment in joints and frame members. The rigidity of joints and frame itself is the source of lateral stiffness in the structure.
2) Shear Wall System: Shear wall system is a lateral load resisting system where in shear walls i.e. either steel paneled walls or reinforced walls are designed from the foundation continuously to the top end of the structure. Shear walls resist lateral loads by cantilever action. The performance or effectiveness of the shear walls is depended upon their position. Thus in this paper different shear wall systems have been analyzed and compared to find the optimum position to provide shear walls.

3) Diagrid Structure: Diagrid structural system is a perimeter frame structure made up of diagonal members which form a diamond shaped element that inherits triangular module or configuration. The RC core acts as a cantilever and the diagrid resists the shear and thus acting together increasing the stiffness of the structure. The main advantage of this system is that is more efficient at resisting lateral loads than other systems. Other advantages of this systems include redundancy i.e. it can transfer the load from a failed portion of the structure to another, it consumes less amount of steel, it has column free exterior, it has no need of providing façade, it has high degree of aesthetics and beauty. Following are the three examples of diagrid buildings: 


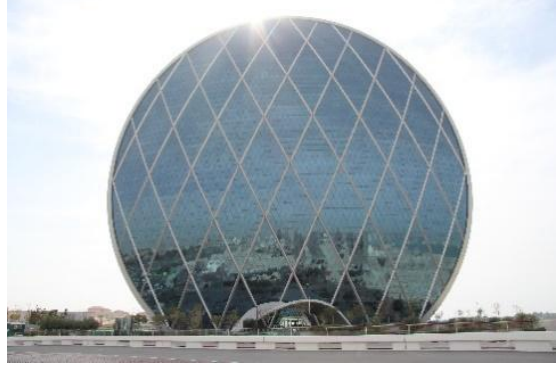

Fig. 1 Aldar Headquaters

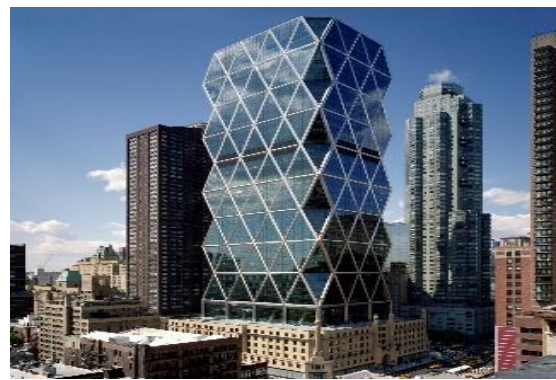

Fig. 2 Hearst Tower, New York

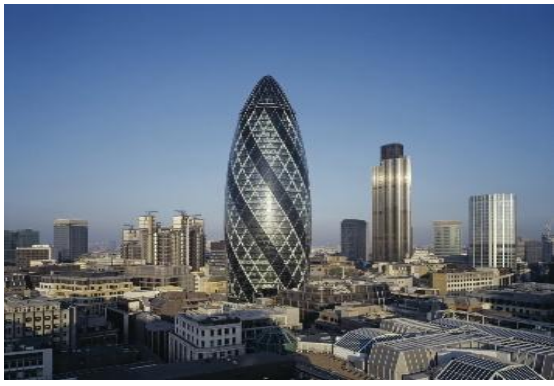

Fig. 3 Swiss Re Buidling, London

\section{OBJECTIVE OF THE PROJECT}

Following are the main objectives of the present study:

- To study shear wall systems.

- To compare the performance of diagrid structural system, shear wall system and simple frame system.

- To study the effects of lateral forces such as wind and earthquake forces on diagrid structural system.

- To perform the comparative study in terms of parameters such as time period, displacement, drift, base shear and steel consumption.

- To obtain optimum position for shear walls to be placed or designed.

\section{MODELLING AND ANALYSIS}

A total number of 12 models have been analyzed, 10 of which are of shear wall systems with different positioning, one is a simple frame structure and one is a diagrid structure. The modelling and the analysis is performed in ETABS and response spectrum method has been utilized for dynamic analysis. Following are the details of the models:

\subsection{Building Data}

Plan:

Number of Storeys:

Typical Storey Height:

Structure Utility:

Load on Beam:

Dead Load:

Live Load:

Seismic Zone:

Seismic Co-eff Factor:

Earthquake Load:

Importance Factor:

Response Reduction

Factor:

Wind Speed:

Wind Load:

Codes:

Steel Design Code:

Load Cases:

\author{
$18 \mathrm{~m} \times 18 \mathrm{~m}$ \\ 37 \\ $3.6 \mathrm{~m}$ \\ Office/ Commercial \\ $14.628 \mathrm{Kn}$ \\ $4 \mathrm{kN} / \mathrm{m}^{2}$ \\ $4 \mathrm{kN} / \mathrm{m}^{2}$ \\ $\mathrm{V}$ \\ 0.36 \\ IS 1893 (Part 1) : 2002 \\ 1 \\ 5 \\ $44 \mathrm{~m} / \mathrm{s}$ \\ IS: 875 (Part 3) - 1978 \\ IS 13920 \& IS 456 \\ IS 800:2007
1) 1.7 (DL + IL)
2) $1.7(\mathrm{DL}+\mathrm{EL})$
3) 1.7 (DL - EL)
4) $1.3(\mathrm{DL}+\mathrm{IL}+\mathrm{EL})$
5) $1.3(\mathrm{DL}+\mathrm{IL}$ - EL)
6) $1.5(\mathrm{DL}+\mathrm{IL})$
7) $1.2(\mathrm{DL}+\mathrm{IL}+\mathrm{EL})$
8) $1.2(\mathrm{DL}+\mathrm{IL}-\mathrm{EL})$
9) $1.5(\mathrm{DL}+\mathrm{EL})$
10) 1.5 (DL - EL)
12) 0.9DL - 1.5EL \\ 11) $0.9 \mathrm{DL}+1.5 \mathrm{EL}$
}

\subsection{Shear Wall System}

For Shear wall systems10 different variations have been modelled and analyzed. Three different thickness of shear walls have been used, i.e. $150 \mathrm{~mm}, 230 \mathrm{~mm}$ and $300 \mathrm{~mm}$. The placement of the shear walls has also been varied in four systems.

First system, at the core in the shape of a C-section as it is usually provided for the elevator shaft. Second system, as L-shaped at all the corners. Third system, at the hollow core so it could act a tubular structure with shear walls forming the shear core.

Fourth system, at the middle of the perimeter of the plan on the outer boundary.

\subsection{Diagrid Structure}

For diagrid structure steel pipe sections have been utilized as diagrids. The size of sections reduces as they are placed in higher storeys i.e. heavier diagrid sections were used in bottom storeys and as the storeys increased lighter diagrid sections were used. The dimensions of the steel pipe diagrid sections used are as follows: $400 \mathrm{~mm}$ diameter and 
$18 \mathrm{~mm}$ thick and similarly $400 \times 15 \mathrm{~mm}, 350 \times 15 \mathrm{~mm}$, $300 \times 15 \mathrm{~mm}$ and $250 \times 15 \mathrm{~mm}$

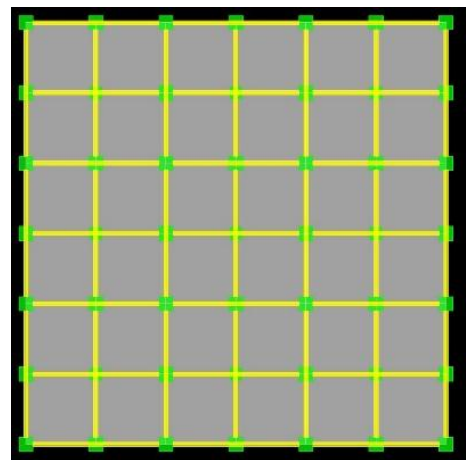

Fig.4 Plan of Simple Frame Structure

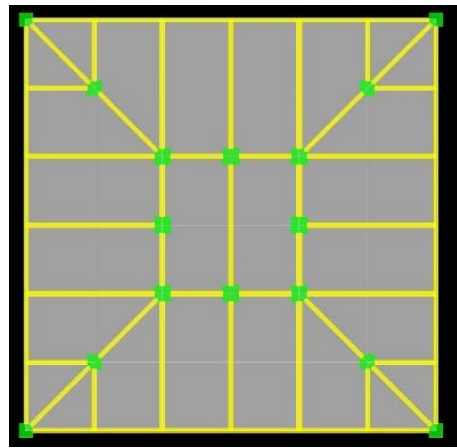

Fig.5 Plan of Diagrid Structure

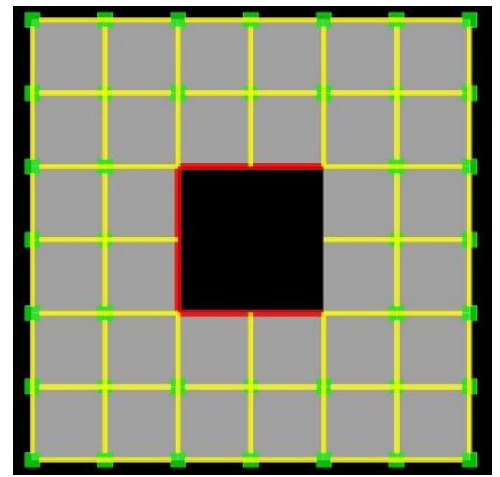

Fig.6 Plan of Shear Wall System 1

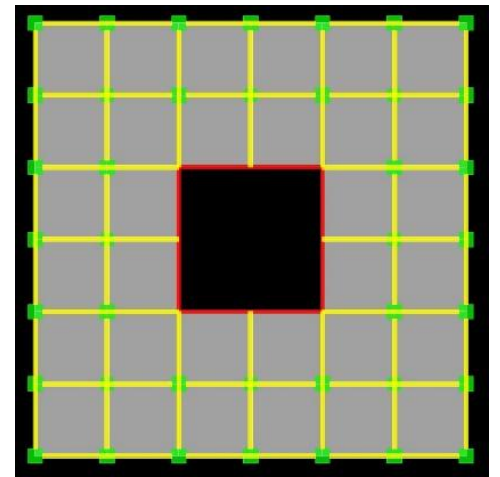

Fig.7 Plan of Shear Wall System 2

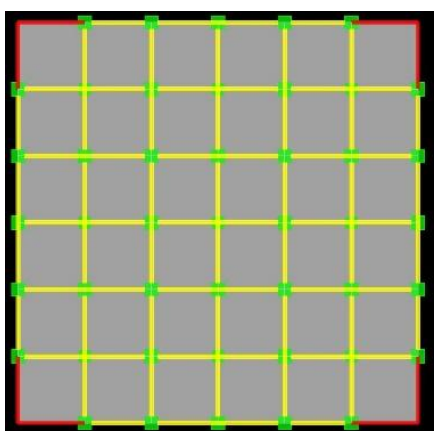

Fig.8 Plan of Shear Wall System 3

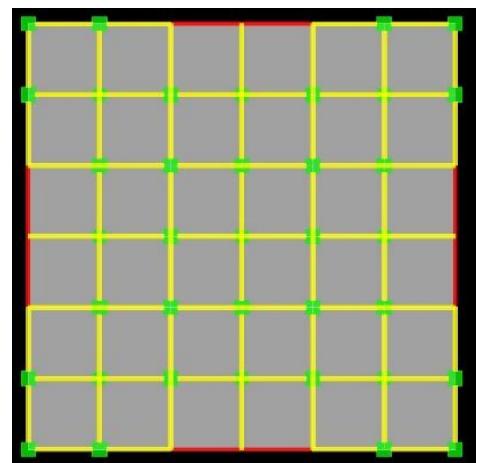

Fig.9 Plan of Shear Wall System 4

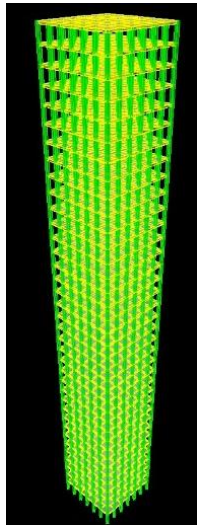

Fig.10 3D View of Simple Frame Structure

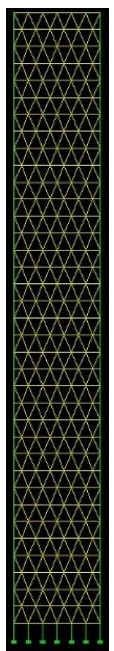

Fig.11 Elevation of Diagrid Structure 


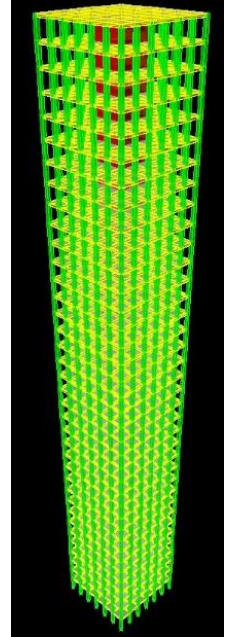

Fig.12 3D View of Shear Wall Systems $1 \& 2$

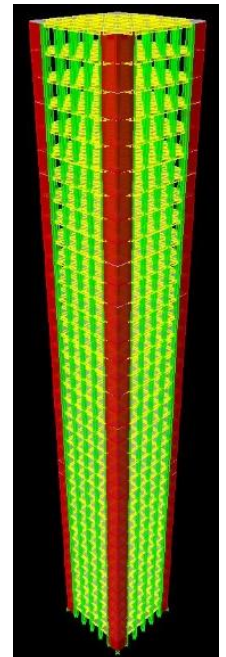

Fig.13 3D View of Shear Wall System 3

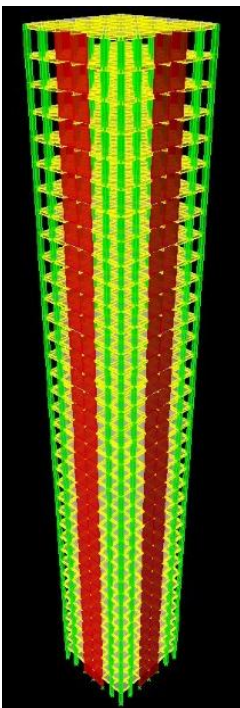

Fig.14 3D View of Shear Wall System 4

\section{ANALYSIS AND RESULTS}

All the 12 models have been modelled and analyzed in ETABS. Dynamic analysis has been performed by Response Spectrum method. Comparative study has been performed using parameters such as lateral displacement, storey drift, stiffness which is governed or is related to base shear and time period of the structure. Following legend has been used for addressing the models during discussion of the results:

\begin{tabular}{|c|c|}
\hline is & Simple Frame Structure \\
\hline DS & Diagrid Structure \\
\hline $\mathrm{CORE}+150$ & $\begin{array}{l}\text { Shear Wall System } 1 \text { with } \\
150 \mathrm{~mm} \text { thick Shear Wall }\end{array}$ \\
\hline $\mathrm{CORE}+230$ & $\begin{array}{l}\text { Shear Wall System } 1 \text { with } \\
230 \mathrm{~mm} \text { thick Shear Wall }\end{array}$ \\
\hline CORE +300 & $\begin{array}{l}\text { Shear Wall System } 1 \text { with } \\
\text { 300mm thick Shear Wall }\end{array}$ \\
\hline $\begin{array}{l}\text { HOLLOW+ } \\
\text { CORE+150 }\end{array}$ & Shear Wall System 2 with \\
\hline$L+150$ & $\begin{array}{l}\text { Shear Wall System } 3 \text { with } \\
150 \mathrm{~mm} \text { thick Shear Wall }\end{array}$ \\
\hline $\mathrm{L}+230$ & $\begin{array}{l}\text { Shear Wall System } 3 \text { with } \\
\text { 230mm thick Shear Wall }\end{array}$ \\
\hline$L+300$ & $\begin{array}{l}\text { Shear Wall System } 3 \text { with } \\
\text { 300mm thick Shear Wall }\end{array}$ \\
\hline MIDDLE+150 & $\begin{array}{l}\text { Shear Wall System } 4 \text { with } \\
150 \mathrm{~mm} \text { thick Shear Wall }\end{array}$ \\
\hline MIDDLE+230 & $\begin{array}{l}\text { Shear Wall System } 4 \text { with } \\
\text { 230mm thick Shear Wall }\end{array}$ \\
\hline MIDDLE+300 & $\begin{array}{l}\text { Shear Wall System } 4 \text { with } \\
\text { 300mm thick Shear Wall }\end{array}$ \\
\hline
\end{tabular}

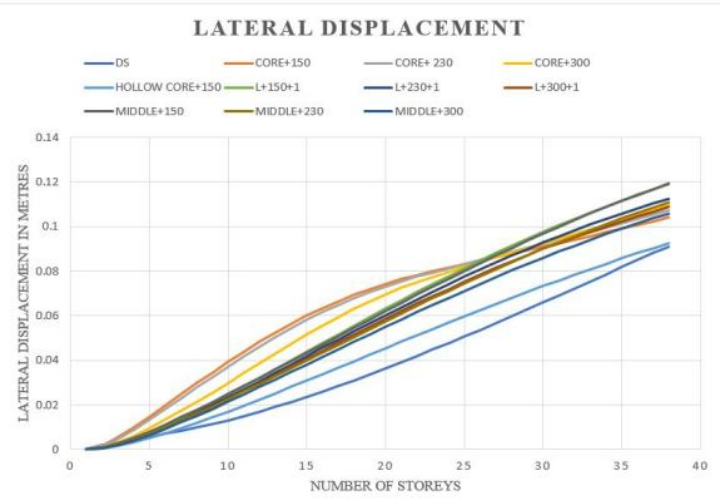

Fig.15 Graph of Lateral Displacements Vs Number of Storeys 


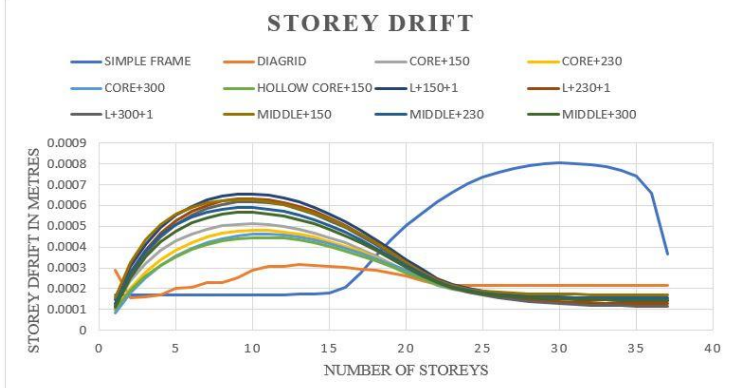

Fig.16 Graph of Storey Drift Vs Number of Storeys

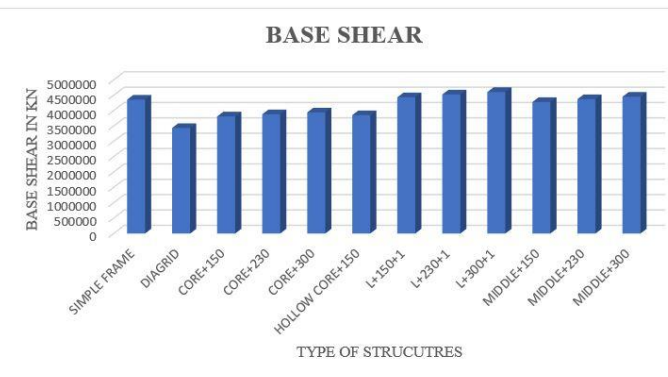

Fig.17 Graph of Base Shear Vs Type of Strcutures

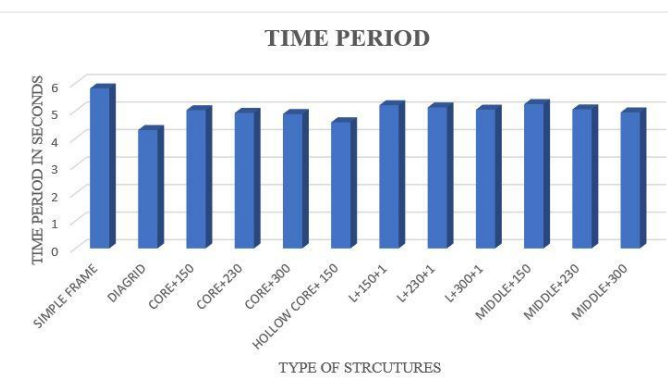

Fig.18 Graph of Time Period Vs Type of Structures

\begin{tabular}{|c|c|c|c|c|}
\hline STRUCTURE & NAX DISPPLACEVENT & MAXDRIFT & VAX BASE SHEAR & TIME PERIOD \\
\hline SS & 0.1437 & 0.000804 & 4358918.347 & 5.81 \\
\hline DIAGRID & 0.091 & 0.000314 & 3435877.803 & 4.3 \\
\hline CORE+150 & 0.1041 & 0.000707 & 3813318.365 & 5.02 \\
\hline CORE+230 & 0.1073 & 0.00048 & 3882463.707 & 4.92 \\
\hline $\mathrm{CORE}+300$ & 0.1096 & 0.00046 & 3942965.881 & 4.88 \\
\hline HOLLOWCORE+150 & 0.0925 & 0.000446 & 38547425.593 & 4.58 \\
\hline $\mathrm{L}+150+1$ & 0.1188 & 0.000655 & 44357937.714 & 5.2 \\
\hline $\mathrm{L}+230+1$ & 0.1125 & 0.000633 & 4527987.503 & 5.12 \\
\hline $\mathrm{L}+300+1$ & 0.1087 & 0.000619 & 4608657.068 & 5.04 \\
\hline IIIDDLE+150 & 0.1193 & 0.000627 & 4282218.331 & 5.24 \\
\hline MIIDDLE+230 & 0.1108 & 0.000588 & 4374412.12 & 5.05 \\
\hline .IIDDLE+300 & 0.1059 & 0.000566 & 4455081.685 & 4.94 \\
\hline
\end{tabular}

In table 1 maximum lateral displacement and maximum drift is in meters, maximum base shear is in kilo-newton $\mathrm{Kn}$ and time period is in seconds. Maximum permissible lateral displacement is $0.2664 \mathrm{~m}$ and maximum permissible storey drift is $0.5328 \mathrm{~m}$. So, all the structures pass the permissible limits. Amongst the shear wall systems, shear wall system 2 is the found out to be most optimum. This may be due its configuration resembling to that of a tubular structure. Due to the hollow core surrounded by shear walls on all four sides, it behaves like a shear core and thus it becomes more efficient than the shear wall system 3 i.e. the L-shaped shear wall system. Even though shear wall system 2 is performing the best, it is not always possible to keep a hollow space for a shear core. That's why the most preferred way to provide shear walls is as shear wall system 1 i.e. a C-section provided mostly at core or any other region of the structure for elevator shaft. But even shear wall system 3 i.e. L -shaped shear walls at corners perform as good as system 1 . So, it can be left up to the structural designer for which shear wall system to be provided. From observing the lateral displacements and storey drift it is seen that diagrid structure has the least lateral displacement and storey drift and hence it is far better than any shear wall systems and therefore superior than simple frame at resisting lateral loads. The time period of diagrid structure is the least suggesting that it has higher stiffness than others. The base shear is least for diagrid structure thus indicating that it is lighter structure than other. A higher base shear indicates either of the three: 1) Highly Stiff Structure 2) Very Heavy Structure \& 3) Location near fault. Since all the models are analyzed for same seismic zone the third reason is invalid in this case. From the lower time period, it has already been established that diagrid has higher stiffness. So, the lower base shear value indicates that the diagrid structure is light as compared to other structures thus implying it is more economical than other structures.

\section{CONCLUSION}

From the analysis results and comparative study put forth in this paper following set of conclusions can be made:

Diagrid Structure overall performs better as lateral load resisting system than simple frame and shear wall systems.

Diagrid Structure has least Maximum Lateral Displacement and Maximum Storey Drift.

Diagrid Structure has higher stiffness than other models.

Diagrid Structure is lighter than other models and thus more economical

Shear wall system 2 is theoretically the best configuration.

Practically shear wall system 3 and shear wall system 1 are best options for providing shear walls.

\section{REFRENCES}

[1]. Barry Charnish and Terry Mc Donnell "The bow: unique Diagrid Structural System for Sustainable Tall Buildings", CTBUH 8th World Congress 2008. 
[2]. Moon, K., Connor, J., and Fernandez, J., "Diagrid Structural System for Tall buildings: Characteristics and Methodology for Preliminary Design", The structural design of tall and special buildings, Vol. 16, pp.205230, 2007.

[3]. Moon, K. S. (2008). "Material Saving Design Strategies for Tall Buildings". CTBUH 8th World Congress.

[4]. Kyoung, Sun Moon. "Diagrid Structures for Complex-Shaped Tall Buildings." Procedia Engineering, 2011: 1343-1350.

[5]. Kyoung, Sun Moon. "Diagrid Structures for Complex-Shaped Tall Buildings." Advanced Materials Research, 2012: 1489-1492.

[6]. Raghunath.D. Deshpande, Sadanand M. Patil, Subramanya Ratan, "Analysis and Comparison of Diagrid and

[7]. Conventional Structural System", International Research Journal Engineering and Technology (IRJET) Volume: 02 Issue: 03 June - 2015.

[8]. Manthan I. Shah, Snehal V. Mevada, Vishal B. Patel, "Comparative Study of Diagrid Structures with Conventional Frame Structures", International Journal of Engineering Research and Applications(IJERA) ISSN: 2248-9622, Vol. 6, Issue 5, (Part - 2) May 2016, pp. 22-29.

[9]. IS: 456-2000. Plain and Reinforced ConcreteCode of Practice (Fourth Revision), Bureau of Indian Standard, New Delhi.

[10]. IS: 1893(Part-I)-2002, Criteria for Earthquake Resistant Design of Structures, Bureau of Indian Standard, New Delhi.

[11]. IS-875(Part-I, Part-II, PartV)-1987 code of practice for design dead loads, live loads and combination of loads.

[12]. IS: 800, "General construction in steel-code of practice", Bureau of Indian Standards, New Delhi, 2007. 